\title{
Prevalence of Femoral Head Ostenecrosis in Patients with Falciform Anemia: A Bibliographic Review in Pediatrics
}

\author{
Valeria Botelho $^{1^{*}}$ (D), Ingridy Caroline Ferreira Silva ${ }^{2}$ (D), Paula Braga Daltro ${ }^{3}$, Indiry \\ Caroline Ferreira Silva ${ }^{4}$ (D), Rodrigo Jorge de Souza da Fonseca ${ }^{5}$ (D), Jane Mary de \\ Medeiros Guimarães $^{6}(\mathrm{D})$, Gildásio Daltro ${ }^{7}$
}

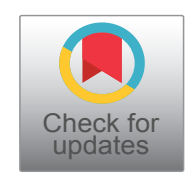

\begin{abstract}
${ }^{1}$ Master's student at the Collective Health Institute of the Federal University of Bahia-ISC / UFBA
${ }^{2}$ Physician, Federal University of Western Bahia. Specialization in progress in Public Health with a concentration in Primary Care-Family Health by the Federal University of Bahia-UFBA
\end{abstract}

${ }^{3}$ Doctoral student, Institute of Collective Health, Federal University of Bahia-ISC/ UFBA

${ }^{4}$ Graduate student of Medicine at the Federal University of Bahia-Multidisciplinary Health Institute-UFBA/IMS

${ }^{5}$ Master's student at the Collective Health Institute of the Federal University of Bahia-ISC / UFBA

${ }^{6}$ Teacher Federal University of the South of Bahia- UFSB

${ }^{7}$ Teacher at the Federal University of Bahia- Faculty of Medicine of Bahia-UFBA/FAMEB, Hospital Edgard Santos- HUPES/UFBA

*Corresponding author: Valéria Lima Botelho, Master's student, Collective Health Institute of the Federal University of Bahia, R. Basilio da Gama, s/n - Canela, Salvador - BA, Brazil. Zip Code: 40110-040, Tel: 71-3283-8136, Fax: 71-3283-8000

\section{Abstract}

Background: Sickle cell disease is a broad term that defines a group of inherited diseases characterized by mutations in the gene that encodes the beta subunit of hemoglobin is a lifelong disease characterized by chronic hemolytic anemia, unpredictable episodes of pain and widespread damage of the organs [1,2]. The prevalence of osteonecrosis in patients with sickle cell disease is high, reaching about $50 \%$ of individuals, with the highest incidence of complications occurring in adolescence. To investigate the prevalence of femoral head ostenecrosis in pediatric patients with sickle cell anemia and to evaluate the associated risk factors.

Methods: An electronic search for studies developed in the last 20 years in the main databases was carried out: PUBMED, SCIELO, MEDLINE and BIREME using the descriptors: Femoral head osteonecrosis, sickle cell anemia, prevalence associated with Boolean operators: or and and Studies published in English, pediatric age range between 0 and 18 years and studies available for access, were adopted as limits. At the end, 28 scientific articles were found. After reading the title and summary, only one study fit for the present bibliographic review was selected, the only study carried out to date on this topic.
\end{abstract}

Results: The present literature review found only one study that carried out with pediatric patients relating sickle cell anemia and osteonecrosis of the femoral head. This study showed that the prevalence of osteonecrosis of the femoral head in the pediatric age group is $39.4 \%$ and is associated with a longer time since the disease was diagnosed ( 97 months), previous trauma in $92 \%$ of cases, and an average score of Charnley 15 points. This was the only study carried out to date that evaluated hip dysfunction and osteonecrosis of the femoral head, and it is urgent and essential to carry out further studies on this subject, given the rapid progression of femoral osteonecrosis. Early diagnosis and thus treatment would guarantee less physical and social suffering for the child.

Conclusion: Thus, from the present bibliographic review, it is concluded that there is an urgent need for further studies that relate the prevalence of osteonecrosis of the femoral head and hip dysfunction in pediatric patients with sickle cell anemia, with a lack of the number of studies carried out in children.

\section{Keywords}

Osteonecrosis, Child health, Sickle cell, Femur head

Citation: Botelho VL, Silva ICF, Daltro PB, Silva ICF, Guimarães JMM, et al. (2020) Prevalence of Femoral Head Ostenecrosis in Patients with Falciform Anemia: A Bibliographic Review in Pediatrics. Int J Pediatr Res 6:064. doi.org/10.23937/2469-5769/1510064

Accepted: June 23, 2020: Published: June 25, 2020

Copyright: (c) 2020 Botelho VL, et al. This is an open-access article distributed under the terms of the Creative Commons Attribution License, which permits unrestricted use, distribution, and reproduction in any medium, provided the original author and source are credited. 


\section{Introduction}

Sickle hemoglobinopathies comprise a variety of diseases that are characterized by the presence of hemoglobin S (HbS). Sickle cell disease is inherited as an autosomal coding trait in individuals who are heterozygous for the $\beta$ Sallele, such as who carry along with the $\mathrm{HbS}$ the $\mathrm{HbA}$ or $\mathrm{HbC}$, known as sickle cell trait (HbAS), or hemoglobin SC disease HbSC while individuals who are homozygous for the $\beta$ S allele (HbSS) have SCA. SCA is the most common form of SCD. Sickle cell disease is a lifelong disease characterized by chronic hemolytic anemia, unpredictable episodes of pain and widespread organ damage $[1,2]$.

Among the Afro-descendants of the new world, the heterozygous genotype reaches $10 \%$ in the USA, more than $6 \%$ in the S-SE of Brazil, and up to $15.7 \%$ in the State of Bahia [1]. In the case of $\mathrm{HbS}$, the highest prevalence occurs in tropical Africa and among blacks from countries that participated in the slave trade [3]. In Brazil, about $0.1 \%$ to $0.3 \%$ of the black population is affected by the disease [4] and it is estimated that there are at least two million HbS carriers (heterozygotes). In the Southeast region, the estimated prevalence of heterozygotes is $2 \%$ in the general population and, among blacks, $6 \%$ to $10 \%$ [5]. In a population-based study [6] in Minas Gerais, the incidence of one new homozygous case was reported for every 2,800 births for sickle cell disease. In the State of Lobo, et al. [7] reported the incidence of a new case of this disease for every 1,196 births.

When analyzing sickle cell anemia in relation to childhood, it is observed that there is a high morbidity and mortality due to, among other factors, the crises of bone infarction, bacterial sepsis, splenic sequestration and also the acute chest syndrome in addition to the deleterious effects of anemia on the physiological development and intellectual of the individual $[1,8]$. In fact, the prevalence of osteonecrosis (ON) in patients with sickle cell disease is high, reaching about $50 \%$ of individuals, with the highest incidence of complications occurring in adolescence $[9,10]$. The involvement of osteonecrosis of both hips is seen in about $40-91 \%$ of patients with ON. As demonstrated by HERNIGOU, et al. [11], progression to femoral head collapse in sickle cell patients occurs in $90 \%$ of cases within two years after the initial diagnosis of stage I osteonecrosis. In addition, the inefficiency and failure of total arthroplasties in these patients are particularly high, with pain incidence and substantial movement limitations in $75 \%$ of sickle cell patients $[12,13]$. These studies suggest that the clinical progression of femoral osteonecrosis in patients with sickle cell disease is more frequent and faster than has been described for other pathologies with non-traumatic osteonecrosis.

Given the above, the present study aims to investigate the prevalence of femoral head ostenecrosis in pediatric patients with sickle cell anemia and to assess the associated risk factors. For that, an electronic search of studies developed in the last 20 years in the main databases was carried out: PUBMED, SCIELO, MEDLINE AND BIREME using the descriptors: Femoral head osteonecrosis, sickle cell anemia, prevalence associated with Boolean operators: or and and. Studies published in English, pediatric age range between 0 and 18 years and studies available for access, were adopted as limits. At the end, 28 scientific articles were selected for the present bibliographic review.

\section{Methods}

An electronic search was performed in the databases: PUBMED, SCIELO, MEDLINE, BIREME on 12/13/19. The following descriptors were used: Femoral head osteonecrosis, sickle cell anemia, prevalence associated with the following Boolean operators: or and and. Initially, when using the Boolean operator or 10684675 articles were found.

For a better selection of articles to be included in this review, the following limits were adopted: 1) Articles in English published in the last 20 years. 2) Pediatric age group - patients between 0 and 18 -years-old.

\section{Results}

For a better delimitation of these for the present review, the Boolean perador was associated, and at the end, 64 eligible articles were found in the 4 databases. After defining these limits, 28 articles were selected. Below is the flowchart specified for each database with that selection.

\section{BIREME/PAHO/WHO - Virtual Health Library}

\section{Database: PUBMED}

Search on: Femoral head osteonecrosis or sickle cell anemia or prevalence.

Total of references: 2781830 studies.

Search on: Femoral head osteonecrosis and sickle cell anemia and prevalence.

Total of references: 40 studies.

Studies published in the last 20 years: 31 studies.

Studies performed on patients from birth to children under 18: 18 studies.

Studies published in English and Portuguese: 14 studies.

Studies available for access: 13 studies (Figure 1).

\section{MEDLINE}

\section{Database: MEDLINE}

Search on: Femoral head osteonecrosis or sickle cell anemia or prevalence.

Total of references: 7763667 


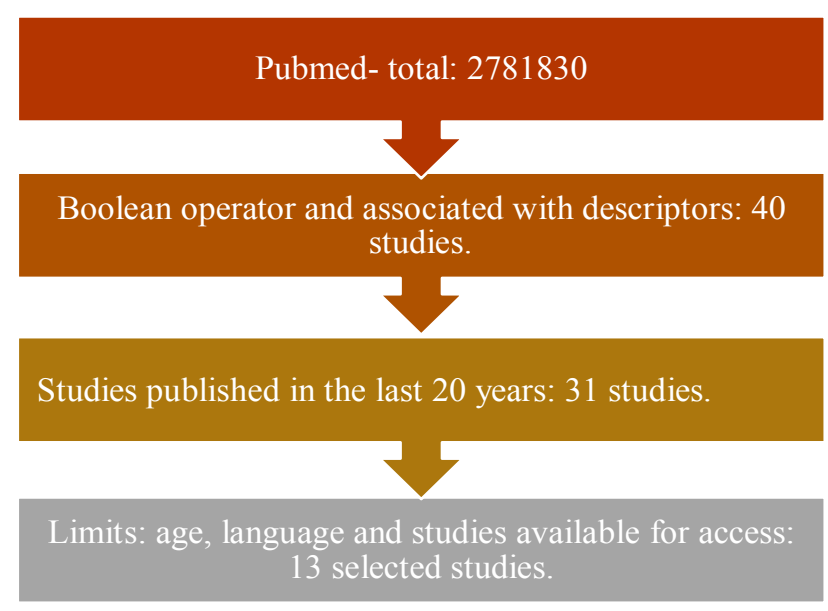

Figure 1: Flowchart - Selection of studies - PUBMED database.

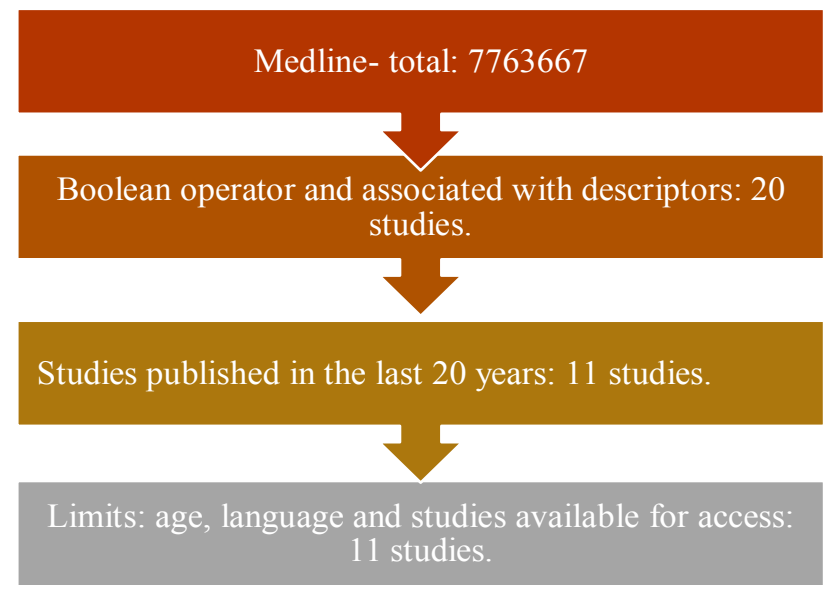

Figure 2: Flowchart - Selection of studies - MEDLINE database.

Search on: Femoral head osteonecrosis and sickle cell anemia and prevalence.

Total of references: 20 studies.

Studies published in the last 20 years: 11 studies.

Studies carried out in patients from birth to children under 18: 11 studies.

Studies published in English and Portuguese: 11 studies.

Studies available for access: 11 studies.

As this data base does not have a filter for the age of the participants, the abstracts of each article were read in order to establish the age range from 0 to 18 years, with 11 studies selected for the present review being selected (Figure 2).

\section{LILACS}

\section{Database: LILACS}

Search on: Femoral head osteonecrosis or sickle cell anemia or prevalence.

Total of references: 139166.

\section{LILACS- total: 139166}

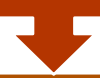

Operador booleano and associada aos descritores: 2 estudos.

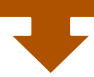

Studies published in the last 20 years: 02 studies.

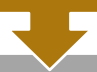

Limits: age, language and studies available for access: 02 studies.

Figure 3: Flowchart - Selection of studies - LILACS database.

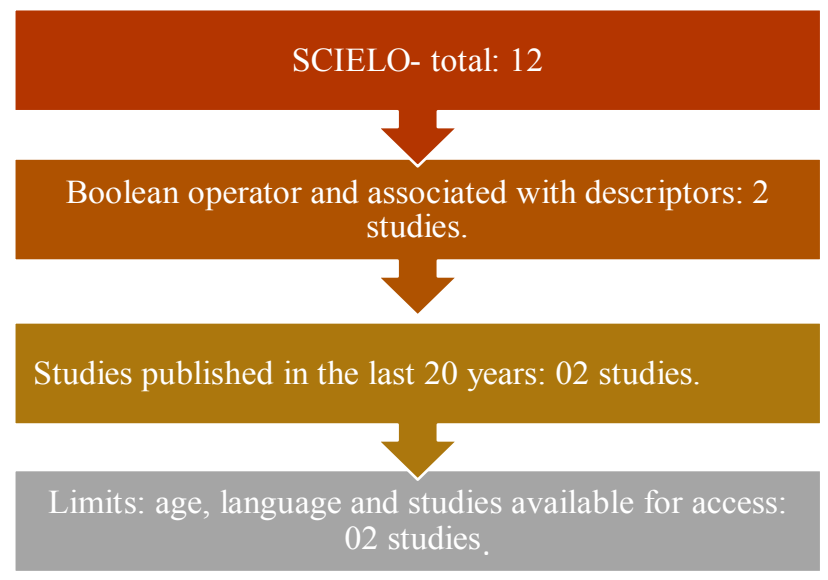

Figure 4: Flowchart - Selection of studies - SCIELO database.

Search on: Femoral head osteonecrosis and sickle cell anemia and prevalence.

Total of references: 2 studies.

Studies published in the last 20 years: 2 studies.

Studies performed on patients from birth to children under 18: 2 studies.

Studies published in English and Portuguese: 2 studies.

Studies available for access: 2 studies (Figure 3).

\section{SCIELO}

Database: SCIELO

Search on: Femoral head osteonecrosis or sickle cell anemia or prevalence.

Total of references: 12 .

Search on: femoral head osteonecrosis and sickle cell anemia and prevalence.

Total of references: 2 studies.

Studies published in the last 20 years: 2 studies. 
Studies performed on patients from birth to children under 18: 2 studies.

Studies published in English and Portuguese: 2 studies.

Studies available for access: 2 studies (Figure 4).

After making the selection of the articles found, the title and abstract were read and the duplicate articles were removed and thus identifying those suitable for the present review. At the end of the selection, only one article was found that showed the prevalence of osteonecrosis of the femoral head in patients diagnosed with sickle cell anemia with hip dysfunction in the pediatric age group, the other studies being excluded.

\section{Discussion}

Avascular necrosis of the hip is a common cause of morbidity in sickle cell disease (SCD). Its prevalence increases with age and pre-disposing factors include a co-existing trait of thalassemia, frequent vaso-occlusive crises, and high hematocrit (Hct) [14]. Seeking to investigate the prevalence of hip fracture in patients with sickle cell anemia in the pediatric age group and after reading the title and summary, only one study was found that analyzed the prevalence of osteonecrosis of the femoral head in patients with sickle cell anemia with hip dysfunction in that range age. A study by Almeida Matos, et al. [15] aimed to verify the prevalence of avascular necrosis of the femoral head in pediatric patients diagnosed with sickle cell anemia, as well as the associated risk factors. For this, across-sectional study was conducted with a group of 92 individuals who had sickle cell disease. Of this total, about 43 individuals had hip dysfunction, and 13 of them were diagnosed with avascular necrosis of the femoral head. Therefore, the overall prevalence of hip fractures in such a study was $39.4 \%$ among patients with hip dysfunction. When comparing with the control group formed by 20 patients, there were no significant differences in demographic variables, however, when comparing the clinical characteristics between the two groups (AVN and control), they showed significant differences in the time of diagnosis of sickle cell disease, previous history of trauma in the hip, presence of pain in the hip and in the mean values of the functional scores, both for right and left hip. When analyzing laboratory tests in the control group, there were higher percentage rates of fetal hemoglobin, platelets and lower rates of total hemoglobin. Possibly, high levels of $\mathrm{HbF}$ act as protection, especially against comorbidities related to vessel occlusion and increased viscosity.

This study concludes that pediatric patients with sickle cell anemia and hip dysfunction have a prevalence of $39.4 \%$ of osteonecrosis of the femoral head, which is associated with a longer time of diagnosis of the disease (97 months), previous trauma in $92 \%$ of the patients. Cases, and an average Charnley score of 15 points. This study concludes that the early evaluation of the hip of children with sickle cell disease, and also the search for risk factors associated with osteonecrosis, can result in greater prevention, early treatment and possible reduction of the sequelae that increase the physical and social suffering of these children. Or the consequences that directly decrease the quality of life of people with sickle cell anemia [15]. It is important to highlight that this is the first study carried out in the scientific literature on the association between clinical hip dysfunction and osteonecrosis of the femoral head in children.

\section{Conclusion}

Through the present bibliographic review, it is concluded that there is an urgent need for further studies that relate the prevalence of osteonecrosis of the femoral head and hip dysfunction in pediatric patients with sickle cell anemia, with a lack of the number of studies carried out in children. The present review found only one study, the first ever carried out in the scientific literature on the association between clinical hip dysfunction and osteonecrosis of the femoral head. It is important to note that early treatment is essential to prevent osteonecrosis of the femoral head in patients with hip dysfunction, and that early diagnosis would guarantee adequate treatment and thus a better quality of life, reducing the physical and social suffering of these children. Thus, it is essential to carry out new studies relating this theme in the pediatric age group.

\section{Statement of Equal Authors' Contribution}

The authors participated in the elaboration of the research, selection of the studies, organization of the content, design of the study as well as in the writing of the content of this systematic review. They also approved the final version to be published and are responsible for all aspects of the work, including ensuring its accuracy and integrity. They also declare that the authors contributed equally.

\section{References}

1. Adorno EV, Couto FD, Moura Neto JP, Menezes JF, Rego $M$, et al. (2005) Hemoglobinopathies in newborns from Salvador, Bahia, Northeast Brazil. Cad Saude Publica 21: 292298.

2. Gregory J. Kato, Frédéric B. Piel, Clarice D. Reid, Marilyn H. Gaston, Kwaku Ohene-Frempong, et al. (2018) Sickle cell disease. Nature Reviews- Primers Disease 4: 18010.

3. Wang WC, Lukens JN (1999) Sickle cell anemia and other sickling syndromes. In: Lee GR, Foerster J, Lukens J, Paraskevas F, Greer JP, et al. Wintrobe's clinical hematology. Williams \& Wilkins, Baltimore (MD), 1346-1397.

4. RamalhoAS, Magna LA, Paivae Silva RB (2003) Government Directive MS \# 822/01: Unique Aspects of Hemoglobinopathies for Public Health in Brazil. Cad Saúde Pública 19: 1195-1199.

5. Ministry of Health, National Health Surveillance Agency (2002) Manual for the diagnosis and treatment of sickle cell diseases. Anvisa, Brasília (DF), 9-11. 
6. Paixão $M C$, Cunha Ferraz $M H$, Januario $J N$, Viana $M B$, Lima JM (2001) Realibility of isoelectrofocusing for the detection of $\mathrm{Hb} \mathrm{S}, \mathrm{Hb} \mathrm{C}$, and $\mathrm{Hb} \mathrm{D}$ in a pioneering population-based program of the new born screening in Brazil. Hemoglobin 25: 297-303.

7. Lobo CLC, Bueno LM, Moura P, Ogeda LL, Castilho S, et al. (2003) Neonatal screening for hemoglobinopathies in Rio de Janeiro, Brazil. Rev Panam Salud Pública 13: 154159.

8. Lúcia Marianoda Rocha Silla (1999) Sicklecell disease: A serious and unknown public health problem in Brazil. Jornal de Pediatria 75: 145-146.

9. Mukisi-Mukaza M, Elbaz A, Samuel-Leborgne Y, Keclard L, Le Turdu-Chicot C, et al. (2000) Prevalence, clinical features, and risk factorsof osteonecrosis of the femoral head among adults with sickle cell disease. Orthopedics 23: 357363.

10. Acurio MT, Friedman RJ (1992) Hip arthroplasty in patiens with sickle-cell haemoglobinopathy. J Bone Joint Surg $\mathrm{Br}$ 74: 367-371.
11. Hernigou P, Habibi A, Bachir D, Galacteros F (2006) The natural history of asymptomatic osteonecrosis of the femoral head in adults with sicklecell disease. J Bone Joint Surg Am 88: 2565-2572.

12. Davis ET, McKee MD, Waddell JP, Hupel T, Schemitsch EH (2006) Total hip arthroplasty following failure of free vascularized fibular graft. J Bone Joint Surg Am 88: 110115.

13. Cheng EY, Thongtrangan I, Laorr A, Saleh KJ (2004) Spontaneous resolution of osteonecrosis of the femoral head. $\mathrm{J}$ Bone Joint Surg Am 86: 2594-2599.

14. Naoum PC, Alvarez F, Domingos CRB, Ferrari F, Moreira HW, et al. (1987) Abnormal hemoglobins in Brazil: prevalence and geographical distribution. Rev Bras Patol Clin 23: 68-79.

15. Marcos Almeida-Matos, Jandrice Carrasco, Luanne Lisle, Marilda Castelar (2016) Avascular necrosis of the femoral head in sickle cell disease in pediatric patients suffering from hip dysfunction. Revista de Saúde Pública 18: 986995. 